\title{
Penifulvin A: A Sesquiterpenoid-derived Metabolite Containing a Novel Dioxa[5,5,5,6]fenestrane Ring System from a Fungicolous Isolate of Penicillium griseofulvum (NRRL 35584)
}

Sang Hee Shim, ${ }^{\dagger}$ Dale C. Swenson,${ }^{\dagger}$ James B. Gloer, ${ }^{*}{ }^{\dagger}$ Patrick F. Dowd, ${ }^{\dagger}$ and Donald T. Wicklow $^{\ddagger}$

${ }^{\dagger}$ Department of Chemistry, University of Iowa, Iowa City, Iowa 52242 and

${ }^{*}$ Mycotoxin Research Unit, Agricultural Research Service, National Center for Agricultural Utilization Research, USDA, Peoria, Illinois 61604

\section{List of Supporting Information}

Figure S1. ${ }^{1} \mathrm{H}$ NMR Spectrum of Penifulvin A (1; $\left.400 \mathrm{MHz}, \mathrm{CDCl}_{3}\right)$

Figure S2. ${ }^{13} \mathrm{C}$ NMR Spectrum of Penifulvin A $\left(\mathbf{1} ; 100 \mathrm{MHz}, \mathrm{CDCl}_{3}\right)$ 


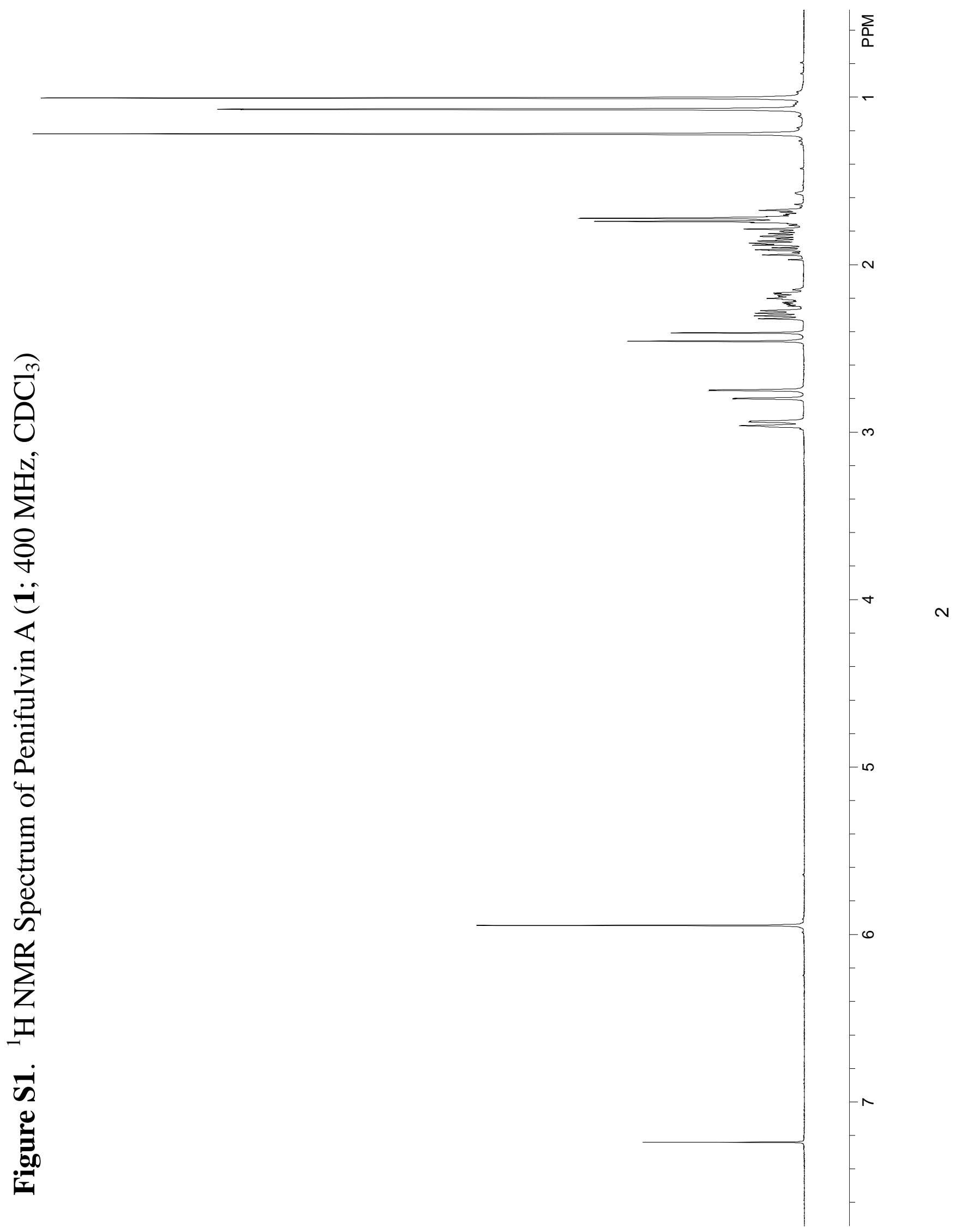




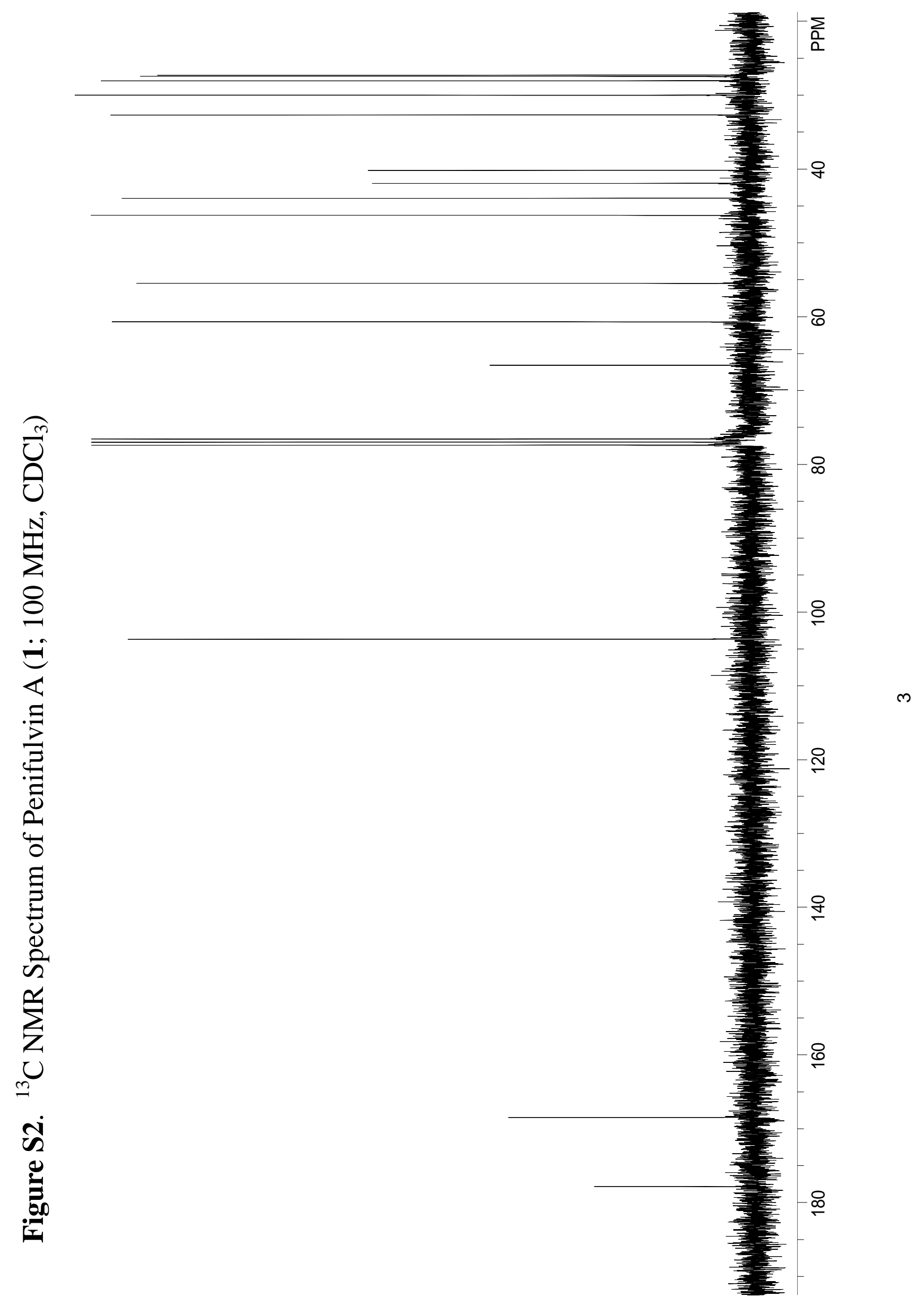

